\section{Water fluoridation, dentition status and bone health of older people in Ireland}

O'Sullivan V, O'Connell BC. Water fluoridation, dentition status and bone health of older people in Ireland. Community Dent Oral Epidemiol 2014. (C) 2014 John Wiley \& Sons A/S. Published by John Wiley \& Sons Ltd.

Abstract - Objective: To examine some of the potential benefits and risks of water fluoridation for older adults. Methods: This study used 'The Irish Longitudinal Study on Ageing', to access a nationally representative sample of 4977 people aged 50 and older. The sample was used to estimate associations between the percentage of households in a respondent's local area with a currently fluoridated water supply and the probability of two binary outcomes: the respondent having all their own teeth and having normal bone density. Past exposure of individuals to fluoridated water was not assessed; the prevalence of fluoridated water in local supplies was obtained from the 2006 Census of Ireland. The Census data indicated that there was considerable variation in the proportion of households with fluoridated water supplies, especially in rural areas. Bone mineral density was estimated from a heel ultrasound of each respondent, and their number of teeth was self-reported. A range of individual variables, such as educational attainment, housing wealth, age and health behaviours, was controlled for. Results: It was found that the greater the percentage of households with a fluoridated water supply in an area, the higher the probability that respondents had all their own teeth. There was no significant relationship between the proportion of households with a fluoridated water supply in an area and bone health. Conclusion: This study suggests that water fluoridation provides a net health gain for older Irish adults, though the effects of fluoridation warrant further investigation.

\author{
Vincent $\mathrm{O}^{\prime}$ Sullivan ${ }^{1,2}$ and Brian C. $\mathrm{O}^{\prime}$ \\ Connell ${ }^{3}$ \\ ${ }^{1}$ The Irish Longitudinal Study on Ageing, \\ Trinity College Dublin, Dublin 2, Ireland, \\ ${ }^{2}$ Lancaster University Management School, \\ Lancaster University, Lancaster, UK \\ ${ }^{3}$ Dublin Dental University Hospital, Trinity \\ College Dublin, Dublin 2, Ireland
}

Key words: ageing; dental caries; osteoporosis; water fluoridation

Brian C. O'Connell,

Dublin Dental University Hospital, Trinity

College, Dublin 2, Ireland

Tel.: +35316127312

Fax: +35316127297

e-mail: brian.oconnell@dental.tcd.ie

Submitted 24 September 2013;

accepted 30 August 2014
The fluoridation of drinking water was described by the U.S. Centers for Disease Control and Prevention as one of 10 Great Public Health Achievements of the 20th century, and this intervention has been widely endorsed as an effective means of reducing tooth decay $(1,2)$. Fluoridation of public water supplies began in Ireland in 1964 and was extended to major cities and towns by 1970; the effects on oral health have been documented in a series of surveys $(3,4)$. The safety of water fluoridation has been extensively reviewed, and it was found to have either no detrimental effect on general health or no clear evidence of toxicity (5-10). Nonetheless, fluoridation is controversial in some communities and suspicion remains that it repre- sents a significant health risk (11-13). Most reviews of water fluoridation have noted the limitations of studies supporting the safety and efficacy of fluoridation and have called for more thorough research of the issue.

While the initial focus of water fluoridation was to prevent caries in children, much less attention has been paid to the effects of fluoridation later in life. There are now large adult populations that have lived several decades with fluoridated water supplies, yet the benefits and risks for these populations are unclear. Assessing the effect of fluoridation on caries in older adults is difficult, as the main outcome - tooth loss - could be the result of other processes, notably periodontal disease, wear, 
trauma and access to dental care $(14,15)$. Similarly, systemic health in adults is strongly influenced by a wide range of individual factors, such as age, gender, income, education, smoking and body mass index. Osteoporosis is a common condition, especially in older women, and predisposes for fractures of the spine, hip, wrist, humerus and pelvis (16). At a molecular level, it is known that fluoride can increase bone mass, although this does not always confer greater fracture resistance $(17,18)$. Ecological studies comparing bone health in fluoridated and nonfluoridated communities have been criticized for failing to control for all possible confounding variables (19-21). A range of bone health indicators has also been considered, such as bone mineral density (BMD) at different skeletal sites and the incidence of various types of fractures. Not surprisingly then, different studies have concluded that water fluoridation (at $1 \mathrm{mg} / \mathrm{l}$ ) could have a positive effect $(22-24)$, no effect $(19,25-28)$ or a negative effect $(29,30)$ on bone health.

The aim of this cross-sectional study was to match data from 'The Irish Longitudinal Study on Ageing (TILDA)' with Census 2006 data on the type of water supply in the local area to assess the relationships between water fluoridation and oral health and bone density in older adults. The TILDA data set contains detailed economic, health and social information on a representative sample of Irish residents aged 50 and above, which allows for a range of variables to be controlled for (31).

\section{Materials and methods}

\section{Sample}

This study used the Health Assessment subsample data from the first wave of TILDA, collected from late 2009 to early 2011 (31). TILDA contains a nationally representative sample of people aged 50 and above (and their spouses or partners of any age) resident in Ireland. The TILDA data set contains detailed information on all aspects of the respondents' lives such as economic circumstances (e.g. employment, pension income and living standards), health (e.g. presence of major diseases, cognitive function, mental health, service needs and access to health care) and social engagement (e.g. contact with friends and kin, formal and informal care and participation in society). The overall response rate among randomly chosen eligible households was $62 \%$. Interviewers carried out faceto-face interviews with respondents in their homes.
These respondents were then invited to undergo a detailed health assessment in either Cork or Dublin, with $62.03 \%$ of the respondents interviewed in their own homes opting to participate in a detailed health assessment. This study used some variables that were measured in the health assessment (bone density and body mass index) so only the respondents who received the health assessment were included in this analysis. To eliminate potential bias due to differential participation by certain groups of people in the health assessment component of TILDA, weights derived from the Irish Central Statistics Office's Quarterly National Household Survey were used to maintain a nationally representative sample in relation to gender, age and educational attainment. A detailed description of the survey methodology and the weighting scheme for TILDA has been published (32). Other respondents were excluded because they did not provide responses relating to the control variables or their electoral district could not be determined (Table 1).

\section{Type of water supply}

In this study, it was not possible to ascertain the fluoridation status of each respondent's water supply, so instead for each individual, we calculated the proportion of households in their electoral district with fluoridated water using data from the 2006 Census of Ireland. Water supplied by local government is required by law to be fluoridated; however, water supplied by local community 'group schemes', or from private wells, is not fluoridated. A small number of local community schemes receive water from local government supplies, so these were counted as fluoridated. According to Census 2006, around $84 \%$ of households have fluoridated water supplies, which is unsurprising given that all of the main urban areas receive local government water supplies. Each local authority is responsible for fluoridating its own water supply within the range of $0.6-0.8 \mathrm{ppm}$. Prior to 2002, the target range for fluoridation was 0.8-1.0 ppm. Local sanitary authorities monitor the fluoridation process daily, while health authorities test fluoride levels monthly and environmental services test on a risk-based assessment. Data from these different bodies is coordinated by local Fluoride Monitoring Committees. A report on the monitoring of water fluoridation between 1990 and 2000 found that unsatisfactory test results $(<0.7$ ppm $\mathrm{F}$ or $>1.1 \mathrm{ppm} \mathrm{F})$ ranged from $2.7 \%$ to $6.9 \%$ per year (33). There is a trend towards more 
Table 1. Proportion of sample with specific characteristics

\begin{tabular}{|c|c|c|c|}
\hline & $\begin{array}{l}\text { TILDA Health } \\
\text { Assessment } \\
\text { sample }\end{array}$ & $\begin{array}{l}\text { Final sample matched with } \\
\text { Census data and excluding } \\
\text { missing values }\end{array}$ & $\begin{array}{l}P \text {-value of difference } \\
\text { between HA sample } \\
\text { and final sample }\end{array}$ \\
\hline All own teeth & 0.10 & 0.10 & 0.952 \\
\hline Some teeth missing, no denture & 0.38 & 0.38 & 0.999 \\
\hline Some teeth missing with partial denture & 0.38 & 0.38 & 0.999 \\
\hline Full denture, no teeth or neither & 0.14 & 0.13 & 0.999 \\
\hline Normal bone density & 0.53 & 0.53 & 0.989 \\
\hline Osteopenia & 0.38 & 0.38 & 0.999 \\
\hline Osteoporosis & 0.09 & 0.09 & 0.904 \\
\hline \multicolumn{4}{|l|}{ Objectively measured BMI } \\
\hline Normal weight & 0.22 & 0.22 & 0.999 \\
\hline Over weight & 0.44 & 0.44 & 0.999 \\
\hline Obese & 0.34 & 0.34 & 0.999 \\
\hline Never lived abroad & 0.78 & 0.78 & 0.999 \\
\hline Exercises at least 1 day/week & 0.29 & 0.30 & 0.985 \\
\hline Current or former smoker & 0.56 & 0.56 & 0.999 \\
\hline Grew up in rural area & 0.58 & 0.57 & 0.989 \\
\hline Female & 0.51 & 0.51 & 0.999 \\
\hline No health insurance or government medical card & 0.12 & 0.12 & 0.999 \\
\hline \multicolumn{4}{|l|}{ Age group } \\
\hline$<65$ & 0.65 & 0.65 & 0.990 \\
\hline $65-74$ & 0.24 & 0.24 & 0.999 \\
\hline$\geq 75$ & 0.11 & 0.11 & 0.999 \\
\hline \multicolumn{4}{|l|}{ Value of home } \\
\hline Renting & 0.08 & 0.08 & 0.999 \\
\hline$<€ 100 \mathrm{k}$ & 0.08 & 0.08 & 0.999 \\
\hline$€ 100-€ 200 \mathrm{k}$ & 0.19 & 0.19 & 0.981 \\
\hline$€ 200-€ 400 \mathrm{k}$ & 0.44 & 0.43 & 0.999 \\
\hline$€ 400-€ 700 \mathrm{k}$ & 0.15 & 0.16 & 0.980 \\
\hline$>€ 700 \mathrm{k}$ & 0.06 & 0.06 & 0.999 \\
\hline Primary education as highest level & 0.32 & 0.31 & 0.986 \\
\hline Secondary education as highest level & 0.46 & 0.47 & 0.988 \\
\hline Tertiary education as highest level & 0.22 & 0.22 & 0.999 \\
\hline \multicolumn{4}{|l|}{ Retrospective self-reported health when aged 14} \\
\hline Excellent & 0.54 & 0.55 & 0.989 \\
\hline Very good & 0.26 & 0.27 & 0.985 \\
\hline Good & 0.12 & 0.12 & 0.999 \\
\hline Fair & 0.04 & 0.04 & 0.999 \\
\hline Poor & 0.02 & 0.02 & 0.999 \\
\hline \multicolumn{4}{|c|}{ Retrospective self-reported family finances when aged 14} \\
\hline Pretty well off & 0.10 & 0.10 & 0.999 \\
\hline About average & 0.67 & 0.67 & 0.999 \\
\hline Poor & 0.23 & 0.23 & 0.999 \\
\hline Fully urbanized area $^{a}$ & & 0.64 & \\
\hline \multicolumn{4}{|l|}{ Prevalence of fluoridation in local electoral district ${ }^{\mathrm{a}}$} \\
\hline $0-29 \%$ of households & & 0.08 & \\
\hline $30-59 \%$ & & 0.11 & \\
\hline $60-89 \%$ & & 0.23 & \\
\hline $91-100 \%$ & & 0.58 & \\
\hline$n$ & 5277 & $4977^{\mathrm{b}}$ & \\
\hline
\end{tabular}

Some of the proportions across certain categories may not sum to one due to rounding.

aThese data come from the 2006 Census.

${ }^{\mathrm{b}}$ Over $90 \%$ of the excluded observations due to missing/refused data on home value.

satisfactory test levels in larger water supplies and a general improvement over time.

The +3500 electoral districts (in a country with a population of just over 4 million) are small enough in population and area to capture local area effects. To achieve a representative sample of the population for different demographic characteristics, the TILDA survey included more respondents in some districts than others. Typically, there were between 5 and 13 respondents from the same district, while some districts had no respondents. No attempt was made to estimate the lifetime expo- 
sure of respondents to fluoridated water or to measure other sources of fluoride intake.

\section{Oral health}

Oral health was assessed using self-reports by the respondents as to whether they chose: I have all my own natural teeth - none missing; I have my own teeth, no dentures - but some missing; I have dentures as well as some of my own teeth; I have full dentures; I have no teeth or dentures. Only 14 observations, $<1 \%$ of the final sample once weights were applied, fell into the latter category so they were added to the 'full dentures' category, although the results are not substantially altered by omitting them altogether.

\section{Bone health}

For those who participated in the health assessment, the BMD of the respondents' nondominant foot was measured using quantitative ultrasound (Achilles Heel Ultrasound; Lunar, Madison, WI, USA). The apparatus for heel evaluation measures both broadband ultrasound attenuation and the speed of sound, both of which are used to calculate an index of bone stiffness (SI) which is a reflection of BMD. Values on this index were classified as follows: Indicative of osteoporosis if SI $\leq 65 \%$, indicative of osteopenia if $65 \% \leq \mathrm{SI} \leq 86 \%$ and indicative of normal if SI $>86 \%$ (34).

\section{Statistics}

Probit models were estimated using maximum likelihood estimation separately for two binary outcomes: having all one's own teeth and having normal BMD. Aside from the prevalence of households with fluoridated water supplies in the local area, the following potentially confounding variables were also controlled for: objectively measured body mass index, whether one ever lived outside the Republic of Ireland, whether or not the respondent exercises at least 1 day/week, ever/currently smoke(d), self-report of growing up in a rural area, gender, coverage by private medical health insurance or government means tested free medical care, age, residing in a noncompletely urbanized electoral district (more than $1 \%$ of local labour force engaged in agriculture), the value of the respondent's home, highest level of education completed, self-reported poor health when aged 14, self-report of family finances when aged 14 and local authority of residence (the +3500 electoral districts are subsets of the 34 local authorities).

\section{Results}

From the original TILDA Health Assessment respondent sample of 5277, just under 300 observations were excluded as they were missing demographic information - in $90 \%$ of cases, this related to the value of their home (Table 1). The electoral district of 10 respondents could not be ascertained, leaving 4977 observations with complete demographic and health assessment data. Descriptive statistics for the outcomes and the control variables are shown in Table 1 . The characteristics of the final working sample are not significantly different from the TILDA Health Assessment sample or the full TILDA sample.

The water supplies of the cities and suburbs of Dublin, Cork, Limerick, Waterford and Galway are fluoridated. However, there was a great deal of variation in the type of water supply in less urbanized and rural areas of the country (Fig. 1). Table 2 shows how the prevalence of households with fluoridated water in electoral districts varied by level of urbanization (as measured by the proportion of the population in the area engaged in

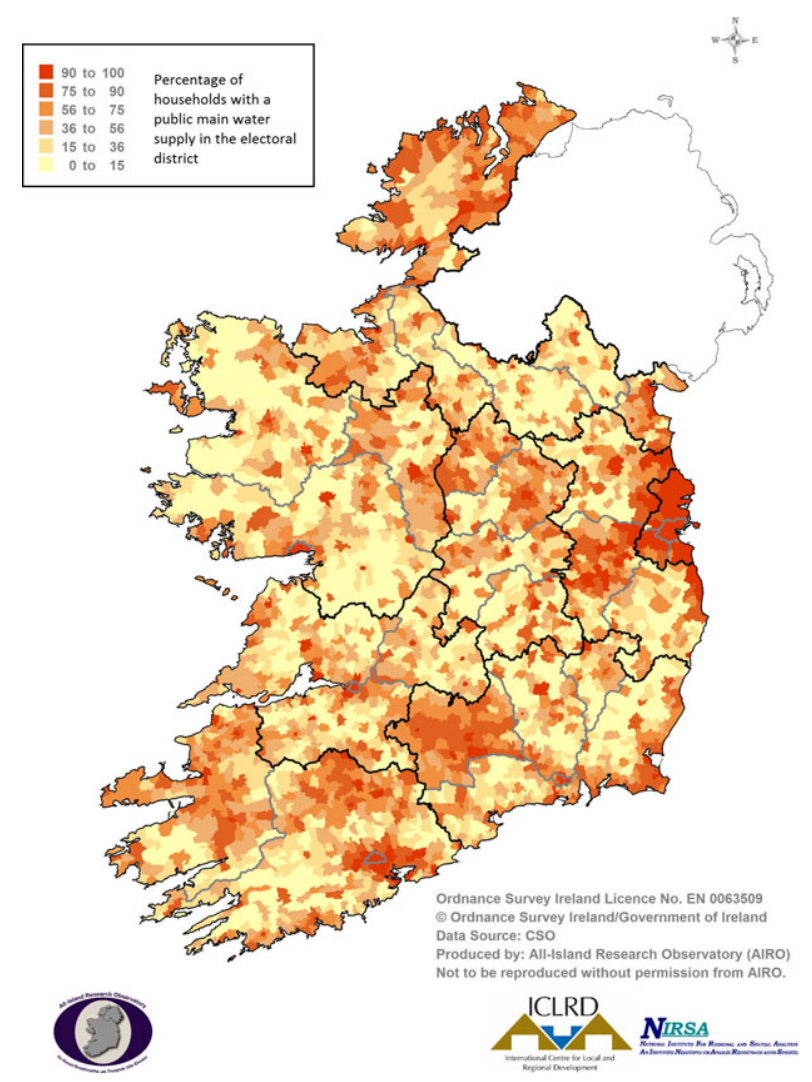

Fig. 1. Prevalence of permanent private households connected to a public main water supply in each electoral district. (Reproduced with permission from the AllIsland Research Observatory). 
Fluoridation, dentition and bone health in older people

Table 2. Prevalence of households with fluoridated water supplies in local electoral districts by level of urbanization, as indicated by the proportion of the labour force engaged in agriculture

\begin{tabular}{lllll}
\hline \multirow{2}{*}{$\begin{array}{l}\text { \% of labour force in local area } \\
\text { engaged in agriculture }\end{array}$} & \multicolumn{2}{l}{ Prevalence of fluoridated households in local district } \\
\cline { 2 - 5 } & $0-29 \%$ & $30-59 \%$ & $60-89 \%$ & $90-100 \%$ \\
\hline$<1 \%$ & 0.00 & 0.00 & 0.02 & 0.15 \\
$1-5 \%$ & 0.00 & 0.00 & 0.56 & 0.85 \\
$6-9 \%$ & 0.03 & 0.08 & 0.48 & 0.33 \\
$10-19 \%$ & 0.16 & 0.28 & 0.29 & 0.09 \\
$20-100 \%$ & 0.34 & 0.35 & 0.03 \\
\hline
\end{tabular}

A $P$-value approaching zero is found for Pearson's Chi-squared test of the categories of urbanization against the prevalence of fluoridated water supply.

${ }^{a}$ Nationally, $7 \%$ of labour force is engaged in agriculture.

Table 3. Average Marginal effects from probit models of having all own teeth and normal bone density

\begin{tabular}{|c|c|c|c|c|}
\hline & \multicolumn{2}{|c|}{$\begin{array}{l}\text { Probability of having all } \\
\text { own teeth }\end{array}$} & \multicolumn{2}{|l|}{$\begin{array}{l}\text { Probability of normal bone } \\
\text { density }\end{array}$} \\
\hline & $\begin{array}{l}\text { Average marginal } \\
\text { effect }\end{array}$ & $P$-value & Average marginal effect & $P$-value \\
\hline Proportion with fluoridation in local electoral district & 0.047 & 0.020 & -0.033 & 0.384 \\
\hline Objectively measured BMI & -0.002 & 0.014 & 0.013 & $<0.001$ \\
\hline Never lived abroad & 0.001 & 0.418 & -0.002 & 0.165 \\
\hline Exercises at least 1 day/week & 0.007 & 0.459 & 0.023 & 0.136 \\
\hline Current or former smoker & -0.027 & $<0.001$ & -0.031 & 0.017 \\
\hline Grew up in rural area & -0.024 & 0.007 & -0.018 & 0.035 \\
\hline Female & 0.005 & 0.569 & -0.261 & $<0.001$ \\
\hline No health insurance (private or social) & 0.009 & 0.401 & -0.020 & 0.490 \\
\hline Age & -0.009 & $<0.001$ & -0.012 & $<0.001$ \\
\hline Nonfully urbanized area & 0.006 & 0.697 & 0.054 & 0.043 \\
\hline \multicolumn{5}{|l|}{ Value of home ( $>€ 700 \mathrm{k}$ reference category) } \\
\hline$<€ 100 \mathrm{k}$ & -0.080 & 0.002 & -0.117 & $<0.001$ \\
\hline$€ 100-€ 200 \mathrm{k}$ & -0.020 & 0.401 & -0.116 & 0.011 \\
\hline$€ 200-€ 400 \mathrm{k}$ & -0.069 & 0.003 & -0.074 & 0.007 \\
\hline$€ 400-€ 700 \mathrm{k}$ & -0.034 & 0.099 & -0.063 & 0.028 \\
\hline \multicolumn{5}{|c|}{ Highest level of education (tertiary as reference category) } \\
\hline Primary & -0.016 & 0.313 & -0.010 & 0.719 \\
\hline Secondary & -0.011 & 0.250 & -0.004 & 0.795 \\
\hline \multicolumn{5}{|c|}{ Retrospective self-reported health when young (poor as reference category) } \\
\hline Excellent & -0.006 & 0.904 & 0.094 & 0.067 \\
\hline Very good & -0.016 & 0.734 & 0.104 & 0.039 \\
\hline Good & -0.022 & 0.653 & 0.044 & 0.395 \\
\hline Fair & -0.020 & 0.734 & 0.083 & 0.201 \\
\hline \multicolumn{5}{|c|}{ Retrospective self-reported family finance when young (poor as reference category) } \\
\hline Pretty well off & 0.039 & 0.002 & 0.003 & 0.889 \\
\hline About average & 0.001 & 0.904 & -0.026 & 0.064 \\
\hline$n$ & 4977 & 4977 & & \\
\hline
\end{tabular}

A set of dummy variables for all 33 local authorities was also adjusted for in the models but the results are not shown here. Local prevalence of fluoridation is based on the electoral district level which is a subset of local authorities.

agriculture). For example, in the least urbanized communities, the population was almost equally divided between districts having 0-29\%, 30-59\% and $60-89 \%$ fluoridated water supplies.

The main findings of this study were that the prevalence of households with fluoridated water in the local electoral district had a statistically significant and positive association with the probability of an older person having all their own teeth, but no significant association with having normal bone density (Table 3 ). In relation to the association between the prevalence of fluoridated water supply among local households and the probability of an individual having all their own teeth, we estimate an average marginal effect of $4.7 \%$ points for those living in areas that are completely 
fluoridated versus those living areas where nobody has a fluoridated water supply.

Extrapolating from the results of the probit models, under a simulation where the entire country were to be completely nonfluoridated but holding all other individual factors constant, the proportion of those over 50 years with their all own teeth would be $8.6 \%$, compared with $10.4 \%$ currently (Table 1). Similarly if, hypothetically, all the households in the country were to have a fluoridated water supply the proportion of the population aged over 50 with all their own teeth would be $12.9 \%$.

In relation to bone health, there was no statistically significant association between the prevalence of households with a fluoridated water supply in an area and the probability that an individual had normal bone density.

The marginal effects of the control variables are also shown in Table 3. The directions and magnitudes of the associations of these variables with oral and bone health were generally consistent with the current literature. For example, increased BMI was found to have a positive association with the probability of having normal bone density, which is widely reported in the literature (35). Higher BMI had a negative association with the probability of having all of one's own teeth. This could be due to diet, where those consuming a high-sugar diet could have a higher BMI and a higher incidence of dental disease.

Living in a nonurbanized area had a positive association with bone health but no effect on oral health. Perhaps surprisingly, education level did not have a significant association with either out- come, although this could be because the model also controlled for housing wealth. The results concerning housing wealth showed that those with lower or no housing wealth had worse oral and bone health than those with high levels of housing wealth.

Gender was not significantly associated with oral health but, as expected, females were far less likely to have normal bone density. Age had a negative and strongly statistically significant relationship with having all of one's own teeth and having normal density. Former or current smokers had worse oral and bone health compared with those who had never smoked. This could be a direct or delayed harmful effect of smoking or could reflect generally poorer health behaviours among smokers.

Those who reported growing up in a rural area had poorer oral health and bone health versus those who grew up in urban areas. This could be related to poorer access to health care when young. Self-reported health when young did not have a statistically significant association with oral health, although those who had better health when young were more likely to have normal bone density.

The models were re-estimated using certain subgroups to test the sensitivity of the results to the inclusion/exclusion of these groups (Table 4). First, the models were re-estimated for those living in nonfully urbanized areas only, to exclude the possibility of urban-rural effects. The effect of the prevalence of fluoridated water was very similar to that found when estimating the model on the entire sample. Furthermore, as osteopenia and osteoporosis are less common in men than in

Table 4 . Sensitivity analysis using subsamples

\begin{tabular}{lr}
\hline & Marginal effect \\
\hline Non-fully urbanised subsample & 0.049 \\
Effect of prevalence of fluoridated water supply on all own teeth & -0.027 \\
Effect of prevalence of fluoridated water supply on normal bone density & 3155 \\
$n$ & 0.061 \\
Women only subsample & -0.022 \\
Effect of prevalence of fluoridated water supply on all own teeth & 2757 \\
Effect of prevalence of fluoridated water supply on normal bone density & 0.020 \\
$n$ & 0.035 \\
Men only subsample & -0.037 \\
Effect of prevalence of fluoridated water supply on all own teeth & 2219 \\
Effect of prevalence of fluoridated water supply on normal bone density & 0.018 \\
$n$ & 0.113 \\
Those aged younger than 55 & -0.094 \\
Effect of prevalence of fluoridated water supply on all own teeth & 0.208 \\
Effect of prevalence of fluoridated water supply on normal bone density & 0.503 \\
$n$ & 0.035 \\
\hline
\end{tabular}


women and to detect any other differences in associations between men and women, the models were estimated separately by gender. The effects of fluoridated water on both outcomes were similar to pooling male and female observations.

The analysis was repeated using different definitions of the outcome variables. In relation to oral health, different binary outcomes were defined through different combinations of answers to the oral health questions and probit models were estimated using these outcomes. The prevalence of fluoridated water supply was estimated to have a negative marginal effect of about four percentage points on having a full denture as opposed to having; all one's own teeth, having no denture but missing some natural teeth or having a partial denture. There was no statistically significant association between the prevalence of fluoridated water supply and having all one's own teeth or missing some teeth but not having a denture, versus partial or full denture. Estimates from ordered probit models with the five different oral status categories as separate outcomes yielded similar results.

Modelling was also repeated for bone density using ordered probit models with three separate outcome categories. From the estimated ordered probit models, no statistically significant associations with fluoridation status were found in relation to being in different categories of bone density.

In the main set of results in Table 3, age was negatively associated with having all one's own teeth and having normal bone density. Table 4 shows the results when re-estimating the model only using those aged $<55$ in 2010 (hence those who lived their teenage years postintroduction of fluoride to Ireland) still yields a positive and significant association between the prevalence of fluoridation and having all one's own teeth.

\section{Discussion}

The addition of fluoride to water supplies began in the United States in the 1940s, in an effort to control dental caries (36). The efficacy of water fluoridation in reducing dental caries was established in the 1950s (37) and other countries began fluoridation programmes (38-40). In Ireland, as the piped water network was expanded not all households in rural areas were linked to local government water supplies, which were mostly fluoridated in the 1960s. Due to the dispersed distribution of the rural population, certain communities were funded to run their own small-scale water supply systems using local water sources, so-called 'group schemes', rather than linking all households to large-scale local authority schemes. The local community 'group schemes', which did not use water from local government sources, served about $3 \%$ of households and were never fluoridated. Furthermore, private wells, serving some $10 \%$ of dwellings, were not fluoridated and the background level of naturally occurring fluoride is generally low. A prefluoridation survey of 660 water supplies found that only five had naturally occurring fluoride levels $>0.3 \mathrm{ppm}$ (33). As a result, less urbanized regions of Ireland have a patchwork of fluoridated and nonfluoridated water supplies serving communities in close proximity.

Initially, it was supposed that only individuals who drank fluoridated water while their teeth were developing would be protected from caries, and so early studies of fluoridation concentrated on coronal caries in children (41). Gradually, it was understood that the main action of fluoride in drinking water is topical, by strengthening tooth surfaces to resist dissolution, promoting remineralization and changing the metabolism of acidogenic bacteria (42). This means that water fluoridation would have ongoing benefits into adulthood, as long as the consumption of fluoridated water continues. It also means that even adults who grew up with non-fluoridated water could be protected against caries by drinking fluoridated water later in life. However, the effect of fluoride in adults has received less attention than in children, partly because it is much more difficult to assess any therapeutic effect. Tooth loss in older adults can be the result of many other causes apart from caries, such as trauma, periodontal disease, tooth wear and access to care (43). These in turn are influenced by general health, income, education and lifestyle (44, 45). Hence, comparison of dental health between populations with different levels of exposure to fluoride is sensitive to a variety of confounding factors. Also, the relative importance of fluoridated water compared with other sources of fluoride, such as diet, toothpaste, mouth rinses and professionally applied topical fluoride is largely unknown in adults.

Millions of adults worldwide have now been consuming fluoridated water for most of their lives and it is important to assess what benefit, if any, this has for the older population. There is growing evidence worldwide that water fluoridation can reduce coronal and root caries, tooth loss and the 
cost of dental care throughout adulthood, although quantification of the effect is hampered by the use of different methodologies and outcomes $(2,14,15$, 46, 47).

The Oral Health of Irish Adults 2000-2002 survey found that after approximately 35 years of fluoridation the 35-44-year-old cohort had a lower prevalence of edentulism (no teeth) compared with their nonfluoridated counterparts $(0.3 \%$ versus $1.2 \%$ ) (4). However, the more than 65-year-old cohort had similar levels of edentulism in fluoridated and nonfluoridated areas $(41.8 \%$ versus $41.5 \%$ ). This finding may be due to the fact that for the age group above 65, fluoridation began after many teeth were already missing and general health or social issues were established. In the present study, the population sample was 50 years old and above, and as expected, tooth loss was strongly related to age. When health, social and lifestyle factors were not considered, it was calculated that more people living in nearly fully fluoridated areas reported having all of their own teeth (12.2\%) compared to those who lived in areas with a low rate of fluoridation $(7.7 \%)$. This difference did not change appreciably once a range of variables was controlled for in the adjusted model (to $12.9 \%$ versus $8.6 \%$ ), suggesting that water fluoridation protects teeth long after they have erupted.

It has been noted that there could be health risks associated with drinking fluoridated water over an extended time and various studies have investigated links between fluoridation and cancer, skin diseases, neurological disorders and skeletal diseases $(6,9,48-50)$. In this study, the prevalence of fluoridated water was not significantly associated with predicted osteopenia and osteoporosis. Using ultrasound of the foot as a measure of BMD, it was found that there was a small negative association between the prevalence of fluoridated water supply and normal bone health; however, the difference was not statistically significant once other factors had been controlled for. While dual-energy $\mathrm{x}$-ray absorptiometry (DXA) remains the definitive technique for the diagnosis of osteoporosis, it involves the use of sophisticated equipment and an exposure to ionizing radiation. Quantitative ultrasound of the calcaneous bone is less costly to perform than DXA scanning and is useful in predicting the risk of pathological fractures (51).

Several other studies have examined the bone health of adults drinking naturally or artificially fluoridated water, but a wide range of methodologies, age ranges, fluoride levels, controls and out- come measures were used, making direct comparisons of the data difficult. The majority of recent publications in different countries have stated that water fluoridation, at therapeutic levels, has either no effect or a slightly protective effect with regard to bone health $(18,19,22,23,26-28$, 52). An increase in hip fractures has been observed in a few studies of fluoridated communities, but these group observations do not prove whether water fluoridation is a risk factor to individuals $(29,30)$. Authors have described a U-shaped dose response of bone fractures/decreased BMD to fluoride concentration, with the lowest incidence of fractures occurring at about $1 \mathrm{mg} / 1$ fluoride in drinking water and higher incidences at very low or high fluoride concentrations (24). While the present study controlled for a number of individual risk factors, it is known that bone health also can be influenced by other confounders, such as calcium intake, vitamin D levels, level of sunlight, oestrogen deficiency and renal function (52). It is also conceivable that sources of fluoride, apart from drinking water, add up to a total intake that is higher than optimal.

This study of Irish adults over 50 years old suggests that water fluoridation has a measurable benefit for this population, although this needs to be more clearly defined. The oral health outcome here was dependent on respondents' own assessment of their natural teeth, which is not wholly reliable. Obviously, the modelling of fluoridated water exposure based on the prevalence of fluoridated supplies in the area is an approximation which is subject to several sources of error and not fully indicative of past exposure. Future studies should include an objective measure of oral health status and individual lifetime assessment of exposure to fluoridated drinking water. To further validate these findings, it would be worthwhile to assess respondents' total fluoride intake and to monitor their general and oral health over time. This should ideally include a range of validated outcomes that reflect the health of major body systems. As with any public health measure, water fluoridation should be subjected to a lifetime economic costbenefit analysis and should be accompanied by public engagement and education.

\section{Acknowledgements}

The Irish Longitudinal Study on Ageing supported this study. We appreciate the input of John Clarkson, Jacinta 
McLoughlin, Rose Anne Kenny, George Savva, Alan Barrett and the rest of the TILDA team. We are grateful to Brendan Whelan for the file to match the TILDA data with Census data.

\section{References}

1. Centers for Disease Control and Prevention (CDC). Recommendations for using fluoride to prevent and control dental caries in the United States. MMWR Morbid Mortal Wkly Rep 2001;50(RR-14):1-42.

2. Petersen PE, Lennon MA. Effective use of fluorides for the prevention of dental caries in the 21st century: the WHO approach. Community Dent Oral Epidemiol 2004;32:319-21.

3. O'Mullane DM, Whelton H. Oral health of Irish adults, 1989-1990: a survey. Dublin: Stationery Office, 1992.

4. Whelton H, Crowley E, O'Mullane D, Woods N, McGrath C, Kelleher V, et al. Oral health of Irish adults 2000-2002. Dublin: Department of Health and Children; 2007.

5. Palmer CA, Gilbert JA, Academy of Nutrition and Dietetics. Position of the Academy of Nutrition and Dietetics: the impact of fluoride on health. J Acad Nutr Diet 2012;112:1443-53.

6. Comber H, Deady S, Montgomery E, Gavin A. Drinking water fluoridation and osteosarcoma incidence on the island of Ireland. Cancer Causes Control 2011;22:919-24.

7. Medical Research Council. Working Group Report: Water Fluoridation and Health. London: Medical Research Council; 2002.

8. Yeung CA. A systematic review of the efficacy and safety of fluoridation. Evid Based Dent 2008;9: 39-43.

9. McDonagh MS, Whiting PF, Wilson PM, Sutton AJ, Chestnutt I, Cooper J, et al. Systematic review of water fluoridation. BMJ 2000;321:855-9.

10. The Stationery Office. Forum on fluoridation 2002: presented to Micheál Martin; [chairman: Patrick F. Fottrell]. Dublin: The Stationery Office; 2002.

11. Cheng KK, Chalmers I, Sheldon TA. Adding fluoride to water supplies. BMJ 2007;335:699-702.

12. Diesendorf M, Colquhoun J, Spittle BJ, Everingham DN, Clutterbuck FW. New evidence on fluoridation. Aust N Z J Public Health 1997;21:187-90.

13. Howard A. Fluoride in the media: a review of newspaper articles from 1999 to 2009. Dent Update 2011;38:86-8, 90-2.

14. Slade GD, Sanders AE, Do L, Roberts-Thomson K, Spencer AJ. Effects of fluoridated drinking water on dental caries in Australian adults. J Dent Res 2013;92:376-82.

15. Griffin SO, Regnier E, Griffin PM, Huntley V. Effectiveness of fluoride in preventing caries in adults. J Dent Res 2007;86:410-5.

16. Budhia S, Mikyas Y, Tang M, Badamgarav E. Osteoporotic fractures: a systematic review of U.S. healthcare costs and resource utilization. Pharmacoeconomics 2012;30:147-70.

17. Kleerekoper M. Fluoride and the skeleton. Crit Rev Clin Lab Sci 1996;33:139-61.
18. National Research Council (U.S.). Committee on fluoride in drinking water. Fluoride in drinking water: a scientific review of EPA's standards. Washington, DC: National Academies Press; 2006.

19. Cauley JA, Murphy PA, Riley TJ, Buhari AM. Effects of fluoridated drinking water on bone mass and fractures: the study of osteoporotic fractures. J Bone Miner Res 1995;10:1076-86.

20. Hillier S, Inskip H, Coggon D, Cooper C. Water fluoridation and osteoporotic fracture. Community Dent Health 1996;13(Suppl 2):63-8.

21. Rosen CJ. Fluoride and fractures: an ecological fallacy. Lancet 2000;355:247-8.

22. Phipps KR, Orwoll ES, Mason JD, Cauley JA. Community water fluoridation, bone mineral density, and fractures: prospective study of effects in older women. BMJ 2000;321:860-4.

23. Kroger H, Alhava E, Honkanen R, Tuppurainen M, Saarikoski S. The effect of fluoridated drinking water on axial bone mineral density - a population-based study. Bone Miner 1994;27:33-41.

24. Li Y, Liang C, Slemenda CW, Ji R, Sun S, Cao J, et al. Effect of long-term exposure to fluoride in drinking water on risks of bone fractures. J Bone Miner Res 2001;16:932-9.

25. Nasman P, Ekstrand J, Granath F, Ekbom A, Fored CM. Estimated drinking water fluoride exposure and risk of hip fracture: a cohort study. J Dent Res 2013;92:1029-34.

26. Hillier S, Cooper C, Kellingray S, Russell G, Hughes $H$, Coggon D. Fluoride in drinking water and risk of hip fracture in the UK: a case-control study. Lancet 2000;355:265-9.

27. Jacobsen SJ, O'Fallon WM, Melton LJ 3rd. Hip fracture incidence before and after the fluoridation of the public water supply, Rochester, Minnesota. Am J Public Health 1993;83:743-5.

28. Suarez-Almazor ME, Flowerdew G, Saunders LD, Soskolne CL, Russell AS. The fluoridation of drinking water and hip fracture hospitalization rates in two Canadian communities. Am J Public Health 1993;83:689-93.

29. Danielson C, Lyon JL, Egger M, Goodenough GK. Hip fractures and fluoridation in Utah's elderly population. JAMA 1992;268:746-8.

30. Jacobsen SJ, Goldberg J, Cooper C, Lockwood SA. The association between water fluoridation and hip fracture among white women and men aged 65 years and older. A national ecologic study. Ann Epidemiol 1992;2:617-26.

31. Barrett A, Burke H, Cronin H, Hickey A, Kamiya Y, Kenny RA, et al. Fifty plus in Ireland 2011: first results from the Irish longitudinal study on ageing (TILDA). Dublin: Trinity College Dublin; 2011.

32. Kearney PM, Cronin H, O'Regan C, Kamiya Y, Savva GM, Whelan B, et al. Cohort profile: the Irish Longitudinal Study on Ageing. Int J Epidemiol 2011;40:877-84.

33. McLoughlin J, Clarkson J, Connolly F, Hargaden J. An evaluation of the delivery and monitoring of water fluoridation in Ireland. Dublin: Department of Health and Children; 2004.

34. Maggi S, Noale M, Giannini S, Adami S, Defeo D, Isaia $G$, et al. Quantitative heel ultrasound in a population-based study in Italy and its relationship with 
fracture history: the ESOPO study. Osteoporos Int 2006;17:237-44.

35. De Laet C, Kanis JA, Oden A, Johanson H, Johnell O, Delmas $\mathrm{P}$, et al. Body mass index as a predictor of fracture risk: a meta-analysis. Osteoporos Int 2005;16:1330-8.

36. Ast DB, Finn SB, Mc CI. The Newburgh-Kingston caries Fluorine study; dental findings after three years of water fluoridation. Am J Public Health Nations Health 1950;40:716-24.

37. Ripa LW. A half-century of community water fluoridation in the United States: review and commentary. J Public Health Dent 1993;53:17-44.

38. Kelman AM. Fluoridation-the Israel experience. Community Dent Health 1996;13(Suppl 2):42-6.

39. Rabb-Waytowich D. Water fluoridation in Canada: past and present. J Can Dent Assoc 2009;75:451-4.

40. Spencer AJ, Slade GD, Davies M. Water fluoridation in Australia. Community Dent Health 1996;13(Suppl 2):27-37.

41. Arnold FA Jr, Dean HT, Knutson JW. Effect of fluoridated public water supplies on dental caries prevalence. Public Health Rep 1953;68:141-8.

42. Featherstone JD. Prevention and reversal of dental caries: role of low level fluoride. Community Dent Oral Epidemiol 1999;27:31-40.

43. Neidell M, Herzog K, Glied S. The association between community water fluoridation and adult tooth loss. Am J Public Health 2010;100:1980-5.

44. Starr JM, Hall RJ, Macintyre S, Deary IJ, Whalley LJ. Predictors and correlates of edentulism in the healthy old people in Edinburgh (HOPE) study. Gerodontology 2008;25:199-204.

45. Astrom AN, Ekback G, Ordell S, Unell L. Sociobehavioral predictors of changes in dentition status: a prospective analysis of the 1942 Swedish birth cohort. Community Dent Oral Epidemiol 2011;39:300-10.

46. Griffin SO, Jones K, Tomar SL. An economic evaluation of community water fluoridation. J Public Health Dent 2001;61:78-86.

47. Maupome G, Gullion CM, Peters D, Little SJ. A comparison of dental treatment utilization and costs by HMO members living in fluoridated and nonfluoridated areas. J Public Health Dent 2007;67: 224-33.

48. Blakey K, Feltbower RG, Parslow RC, James PW, Gomez Pozo B, Stiller C, et al. Is fluoride a risk factor for bone cancer? Small area analysis of osteosarcoma and Ewing sarcoma diagnosed among 0-49-yearolds in Great Britain, 1980-2005. Int J Epidemiol 2014;43:224-34.

49. Lamberg M, Hausen H, Vartiainen T. Symptoms experienced during periods of actual and supposed water fluoridation. Community Dent Oral Epidemiol 1997;25:291-5.

50. SCHER. Opinion on critical review of any new evidence on the hazard profile, health effects, and human exposure to fluoride and the fluoridating agents of drinking water. Brussels: Directorate General for Health and Consumers, European Commission; 2011.

51. Floter M, Bittar CK, Zabeu JL, Carneiro AC. Review of comparative studies between bone densitometry and quantitative ultrasound of the calcaneus in osteoporosis. Acta Reumatol Port 2011;36:327-35.

52. Demos LL, Kazda H, Cicuttini FM, Sinclair MI, Fairley CK. Water fluoridation, osteoporosis, fracturesrecent developments. Aust Dent J 2001;46:80-7; quiz 143. 